\title{
Prevalence of Atopic Disorders in Inner-City Asian Americans and the Predictive Value of Family History
}

\author{
Mary Lee-Wong ${ }^{1 *}$, Vivian Chou ${ }^{1}$, Merhunisa Karagic ${ }^{2}$, Shirley Gomez ${ }^{1}$, Leonardo Moqattash ${ }^{3}$, Nanette B Silverberg ${ }^{4}$, Jonathan I Silverberg ${ }^{4}$ \\ and Reuben Abraham ${ }^{1}$
}

${ }^{1}$ Department of Medicine, Division of Allergy, Asthma and Immunology, Beth Israel Medical Center, NY, USA

${ }^{2}$ Ross University School of Medicine, USA

${ }^{3}$ AUA College of Medicine, USA

${ }^{4}$ Department of Dermatology, St. Luke's-Roosevelt Hospital and Beth Israel Medical Center, USA

\begin{abstract}
Background: Increasing prevalence of allergic disorders has been observed over the last fifty years. The disparate rates of allergic disorders have been well-characterized in several minority groups. However, few studies have reported the distribution of atopic disorders among Asian Americans.

Objective: To gain a greater understanding of the prevalence of atopic disorders in Asian Americans presenting to an Allergy Clinic.

Methods: A retrospective chart review was performed on 471 Asian American patients receiving treatment in an inner city allergy clinic located in New York. Family history and past medical history of asthma, allergic rhinitis, atopic dermatitis, food allergy, and drug allergy were recorded. The patients were primarily of Chinese, Japanese or Korean origin; $34 \%$ male $(n=158), 66 \%$ female $(n=313)$, with a mean age of $32 \pm 12.9$ years.

Results: Allergic rhinitis $(62 \%)$ and atopic dermatitis $(50 \%)$ were more prevalent $(P<0.001)$ than asthma $(21 \%)$ Proportions reporting a past medical history of allergic rhinitis, atopic dermatitis, food allergy, asthma, and drug allergy were $62 \%, 50 \%, 33 \%, 21 \%$, and $21 \%$ respectively, with corresponding family history proportions of $44 \%$, $28 \%, 17 \%, 24 \%$, and $9 \%$. Using the McNemar test for correlated proportions, highly significant associations between family and past medical history were observed for allergic rhinitis and atopic dermatitis $(p<.001)$, but not for asthma $(p=0.38)$.

Conclusion: Allergic rhinitis and atopic dermatitis were the dominant atopic disorders in this population. This data also suggests that a family history is strongly predictive of prevalence of atopic disorders such as allergic rhinitis and atopic dermatitis, but not asthma, among Asian Americans presented at our inner-city allergy clinic.
\end{abstract}

Keywords: Atopic dermatitis; Atopy; Prevalence of atopic disorders; Asian-Americans; Family history

\section{Introduction}

Increase in the prevalence of allergic disorders such as asthma, allergic rhinitis, and atopic dermatitis have been observed over the last fifty years [1-3]. However, the mounting incidence of allergic diseases is not uniform amongst human subpopulations and varies by country. Disparate rates of allergic disorders, according to race, have recently been documented [4]. Understanding the differences between ethnic groups can help us address our patients' medical needs. These differences have been especially well-characterized in some minority groups such as African and Hispanic Americans [5]. Asian Americans, amongst other minorities have been flagged as a group for which underreporting of atopic dermatitis has been problematic in published literature [6].

The 2010 United States census revealed that the Asian American population has expanded more rapidly than any other major racial group in the preceding decade, having grown by 43 percent. Asian Americans currently comprise five percent of the US population [7]. Until recently, there has been a lack of sufficient research regarding the prevalence of allergic disorders in Asian Americans as compared to other ethnic minority groups in the United States. In some Asian countries, asthma prevalence has tripled over the past twenty years [8]. Leung et al. found that family history was linked with asthma and allergic symptoms in Hong Kong, Malaysia, and China, conferring a 3 to
80 fold increase in risk to family members and was a stronger predictor for asthma and allergy than atopy [9]. A study done in California showed that African-Americans were more susceptible to having non-atopic asthma as opposed to Asian-Americans, who had a higher prevalence of asthma and other atopic conditions [10]. Emerging data from California has further demonstrated that annual hospitalization rates for asthma have increased for Asian Americans [11]. In contrast, Lee et al. found that Boston schoolchildren with Asian surnames were less likely to be diagnosed with asthma [12]. A study of mixed ethnic patients demonstrated that Asian and Pacific Islanders were two to six times more likely to visit a doctor for their Atopic Dermatitis (AD) or psoriasis than Caucasians [13]. However, there is still a relative paucity of literature examining the nature of allergic disorders in minorities, especially Asian-Americans. Our study surveyed Asian American

*Corresponding author: Mary Lee-Wong, Department of Medicine, Division of Allergy, Asthma and Immunology, Beth Israel Medical Center, Suite \# 3F, 10 Union Square East, New York, NY 10003, USA, Tel: (212)420-4013; Fax: (212)844-6786; E-mail: mleewong@chpnet.org

Received October 29, 2012; Accepted December 12, 2012; Published December 18,2012

Citation: Lee-Wong M, Chou V, Karagic M, Gomez S, Moqattash L, et al. (2013) Prevalence of Atopic Disorders in Inner-City Asian Americans and the Predictive Value of Family History. J Aller Ther 4: 127. doi:10.4172/2155-6121.1000127

Copyright: (c) 2013 Lee-Wong M, et al. This is an open-access article distributed under the terms of the Creative Commons Attribution License, which permits unrestricted use, distribution, and reproduction in any medium, provided the original author and source are credited. 
patients in a New York inner city clinic, with a focus on recognizing the dominant atopic disorders that affected the Asian American population.

\section{Methods}

A retrospective chart review was performed on 471 Asian American patients seen at a New York City outpatient Allergy and Immunology (Beth Israel Medical Center) practice over a one year time period. The practice location is one to two miles from China town in New York City. Inclusion criteria were attendance at an allergy clinic and self identification as Asian American. Patients were either self- referred or referred by a physician. The data collected included:

- Age

- Sex

- Race (subgroup of Asian Americans)

- Past medical history of allergic rhinitis, atopic dermatitis, food allergy, asthma, or drug allergy

- Family history of allergic rhinitis, atopic dermatitis, food allergy, asthma, or drug allergy

Data was extracted and recorded onto an Excel spreadsheet and statistical analyses were performed with SPSS for Windows (Version 12). The Mc-Nemar test for correlated proportions was used to determine the $\mathrm{p}$-values.

\section{Results}

The patients were primarily of Chinese, Japanese or Korean origin, $66 \%$ female $(n=313)$, and had a mean age of $32 \pm 12.9$ years. Allergic rhinitis (62\%) and atopic dermatitis (50\%) were more prevalent $(\mathrm{P}<0.001)$ than asthma $(21 \%)$ (Table 1$)$. Proportions reporting a past medical history of allergic rhinitis, atopic dermatitis, food allergy, asthma, and drug allergy were $62 \%, 50 \%, 33 \%, 21 \%$, and $21 \%$ respectively, with corresponding family history proportions of $44 \%, 28 \%, 17 \%, 24 \%$, and $9 \%$ (Table 1). Using the McNemar test for correlated proportions, highly significant associations between family and past medical history were observed for allergic rhinitis and atopic dermatitis (for each, $\mathrm{p}<0.001$ ), but not for asthma $(\mathrm{p}=0.38$ ) (Table 1). Males tended to report lower proportions of family and past medical history for allergic rhinitis and atopic dermatitis than females, but not for asthma.

\section{Discussion}

Until recently, there has been a lack of sufficient research regarding the prevalence of allergic disorders in Asian Americans as compared to other ethnic minority groups in the United States. There has been limited data published on the breakdown of prevalence of atopic disorders amongst Asian Americans.

In recent years, much attention has been focused on the TIM gene family on chromosome 5, 5q 23-25, and its significance in playing an

\begin{tabular}{|l|l|l|l|}
\hline Atopic disorder & $\begin{array}{l}\text { Past medical history } \\
\text { percent prevalence } \\
\text { (n=471) }\end{array}$ & $\begin{array}{l}\text { Family history } \\
\text { percent prevalence } \\
\text { (n=471) }\end{array}$ & $\begin{array}{l}\text { P value (by } \\
\text { McNemar test) }\end{array}$ \\
\hline Allergic rhinitis & $62 \%$ & $44 \%$ & $<0.001$ \\
\hline Atopic dermatitis & $50 \%$ & $28 \%$ & $<0.001$ \\
\hline Food allergy & $33 \%$ & $17 \%$ & $<0.001$ \\
\hline Asthma & $21 \%$ & $24 \%$ & 0.382 \\
\hline Drug allergy & $21 \%$ & $9 \%$ & $<0.001$ \\
\hline
\end{tabular}

Table 1: Breakdown of past medical history and family history of atopic disorders. important role in atopic diseases. Specifically, TIM-1 and TIM-3 have been postulated to play pivotal role in the development of allergic disorders $[14,15]$. In one study by Mou et al. two SNPs identified in the TIM-1 promoter region were found to play an important role in the susceptibility of the Han Chinese population to allergic rhinitis [15]. In a different study by Chae et al. different polymorphisms were identified on the TIM gene in a Korean population which was associated with asthma susceptibility [16]. Liu et al. also reported that a promoter polymorphism in the TIM-1 gene is significantly associated with the risk of developing asthma [13]. In contrast, Noguchi et al. found that in Japanese pediatric asthma patients, seven polymorphisms were identified in the TIM-1 gene with no association with asthma. In addition, patients were screened for polymorphisms in the TIM3 gene, but none were identified [14]. Therefore, genetic factors need to be considered when discussing trends in the prevalence of atopic diseases, and may account for the atopic groupings noted in our patient population.

The pathogenesis of allergic disorders has been studied extensively. It is now understood that $\mathrm{T}$ cells play a key role in allergic inflammatory and hypersensitivity response. The overproduction of $\mathrm{Th}-2$ through the production of cytokines (IL-4, IL-5, and IL-13) leads to IgE synthesis, mast cells activation, eosinophil growth and differentiation and hyperresponsiveness of the airways [17]. Studies of hygiene hypothesis propose that the strong interplay between genetics and environment skew the immune system towards a Th-2 predominant response, resulting in atopy $[18,19]$. More in-depth genome wide association studies have concluded that SNPs on different genes and chromosomes play a crucial role in the allergic inflammatory mechanism [20] and that different HLA gene loci are associated with the etiology of pediatric asthma [14].

Allergic rhinitis and atopic dermatitis were the dominant atopic disorders in our population of adult Asian American patients. This concurs with incidence data from the California Healthy Kids Survey, which found that Filipinos were most likely to have asthma, followed by Pacific Islanders, Japanese, Indians, Chinese, Vietnamese, Cambodians, Laotians, and Koreans. Males had lower proportions of family and past medical history than females for allergic rhinitis and atopic dermatitis, but not for asthma. A study comparing African American Caucasian and Asian American populations showed that Asian American populations are at a higher risk of developing asthma with hay fever (atopic asthma) than Caucasians, while African Americans are at higher risk of developing asthma without hay fever (non-atopic asthma). In addition, Asian Americans experienced more hay fever than Caucasians and African Americans, suggesting that Asians are more prone to developing atopic conditions [18].

Our data also suggests that a family history is strongly predictive of prevalence of the atopic disorders such as allergic rhinitis and atopic dermatitis, but not of asthma, among Asian Americans presenting at an inner-city allergy clinic. The fact that family history was not predictive of asthma in this population suggests that environmental factors may play a larger role in the development of asthma, relative to the other atopic disorders. In three Chinese populations: Hong Kong, Kota Kinabalu and $\mathrm{San} \mathrm{Bu}$, it was found that the two most common inhaled allergens causing sensitization in $95 \%$ of school children using skin prick testing were dust mites and cockroach [7]. Further studies suggest that low socioeconomic status may be an important factor in the development of allergic disorders [5]. The recent US Census showed that Asian Americans are more likely to live below the poverty line and hence have a lower socioeconomic status than non-Hispanic whites 
Citation: Lee-Wong M, Chou V, Karagic M, Gomez S, Moqattash L, et al. (2013) Prevalence of Atopic Disorders in Inner-City Asian Americans and the Predictive Value of Family History. J Aller Ther 4: 127. doi:10.4172/2155-6121.1000127

Page 3 of 3

[17]. The clinic at which this study was performed services in Manhattan neighborhoods with a high concentration of Asian Americans, many of whom have low incomes. Thus, environmental exposures can play a substantial role in the development of atopic disorders and may explain the escalating asthma prevalence in this population.

Further studies may pursue the role of low socioeconomic status and genetic polymorphisms on the development of allergic disorders. As evidenced by the recent US Census, Asian Americans are at a proportionally higher risk of living in a low socioeconomic class than non-Hispanic whites [17]. Further studies may clarify the role of genetic makeup versus environmental factors in the development of atopic disorders.

\section{References}

1. Sly RM (1999) Changing prevalence of allergic rhinitis and asthma. Ann Allergy Asthma Immunol 82: 233-248.

2. Larsen FS, Hanifin JM (2002) Epidemiology of atopic dermatitis. Immuno Allergy Clinics NA 22: 1-25

3. Laughter D, Istvan JA, Tofte SJ, Hanifin JM (2000) The prevalence of atopic dermatitis in Oregon schoolchildren. J Am Acad Dermatol 43: 649-655.

4. Robinson MK (2002) Population differences in acute skin irritation responses Race, sex, age, sensitive skin and repeat subject comparisons. Contact Dermatitis 46: 86-93.

5. Litonjua AA, Carey VJ, Weiss ST, Gold DR (1999) Race, socioeconomic factors, and area of residence are associated with asthma prevalence. Pediatr Pulmonol 28: 394-401.

6. Hirano SA, Murray SB, Harvey VM (2012) Reporting, representation, and subgroup analysis of race and ethnicity in published clinical trials of atopic dermatitis in the United States between 2000 and 2009. Pediatr Dermatol 29 : 749-755.

7. US Census Bureau. Washington, USA.

8. Leung TF, Wong GW (2008) The Asian side of asthma and allergy. Curr Opin Allergy Clin Immunol 8: 384-390.

9. Leung R, Ho P, Lam CW, Lai CK (1997) Sensitization to inhaled allergens as a risk factor for asthma and allergic disease in Chinese population. J Allergy Clin Immunol 99: 594-599.

10. Lee-Wong M, Chou V, Silverberg JI (2012) A study of IgE sensitization and skin response to histamine in Asian-Pacific American adults. Allergy Asthma Proc 33: $341-347$

11. Von Behren J, Kreutzer R, Smith D (1999) Asthma hospitalization trends in California, 1983-1996. J Asthma 36: 575-582.

12. Lee T, Brugge D, Francis C, Fisher O (2003) Asthma Prevalence Among InnerCity Asian American Schoolchildren. Public Health Rep 118: 215-220.

13. Liu Q, Shang L, Li J, Wang P, Li H, et al. (2007) A functional Polymorphism in the TIM-1 Gene Is Associated with Asthma in a Chinese Han Population. Int Arch Allergy Immunol 144: 197-202.

14. Noguchi E, Nakayama J, Kamioka M, Ichikawa K, Shibasaki M, et al. (2003) Insertion/deletion coding polymorphisms in hHAVcr-1 are not associated with atopic asthma in the Japanese population. Genes Immun 4: 170-173.

15. Mou Z, Shi J, Tan Y, Xu R, Zhao Z, et al. (2010) Association Between TIM1 Gene Polymorphisms and Allergic Rhinitis in a Han Chinese Population. $J$ Investig Allergol Clin Immunol 20: 3-8.

16. Chae SC, Song JH, Lee YC, Kim JW, Chung HT (2003) The association of the exon 4 variations of Tim-1 gene with allergic diseases in a Korean population. Biochem Biophys Res Commun 312: 346-350.

17. Chen JT, Krieger N, Van Den Eeden SK, Quesenberry CP (2002) Different Slopes for Different folks: Socioeconomic and Racial/Ethnic Disparities in Asthma and Hay Fever among 173,895 U.S. Men and Women. Environ Health Perspect 110: 211-216

18. von Mutius E, Weiland SK, Fritzsch C, Duhme H, Keil U (1998) Increasing prevalence of hay fever and atopy among children in Leipzig, East Germany. Lancet 351: 862-866.

19. Noguchi E, Sakamoto H, Hirota T, Ochiai K, Imoto Y, et al. (2011) Genome-Wide Association Study Identifies HLA-DP as a Susceptibility Gene for Pediatric Asthma in Asian Populations. PLoS Genet 7: e1002170.

20. Davis AM, Kreutzer R, Lipsett M, King G, Shaikh N (2006) Asthma Prevalence in Hispanic and Asian American Ethnic Subgroups: Results from the California Healthy Kids Survey. Pediatrics 118: e363-e370. 